British Islands and the more temperate parts of Europe it is very possibly only the young of this species which migrate, and the adults, having once fixed on a place of residence, may stick to it; so that here we have a case which will almost bear out $\mathrm{Mr}$. Wallace's supposition. With this, however, he stops, and I am sorry to say offers no suggestion as to the way in which migration is effected.

The question which Mr. Romanes puts would be more appropriately answered by $\mathrm{Mr}$. Tegetmeier, and I hope he will be induced to do so. I can only say that that gentleman has repeatedly urged his views on me in conversation and upon the public in his books (see "Pigeons, their Structure," \&c., pp. 84,85 , and "The Homing or Carrier Pigeon," pp. 37-42, I05 $-\mathbf{1} 18$ ) which, being ready of access, I need not here quote. To limit myself to what I am alone answerable for, I would say that when declaring that sight alone cannot be much aid to birds while migrating, I had especially in mind the almost peculiar case of the Scandinavian form of Bluethroat (Ruticilla surcica), which winters in Egypt and the Nile Valley, and summers in the northern or mountainous parts of Sweden, Norway, Finland, and Russia; while, though no doubt passing regularly twice a year over the intervening countries of Europe, it is there so singularly scarce as to have been, until of late years, almost unknown to the best of German ornithologists. For the benefit of such of my readers as are unacquainted with the bird, I may add that the cock has a conspicuous and beautiful plumage, a fine song, and habits which, in the spring of the year, cannot be called unobtrusive. If, therefore, it did commonly occur in Germanywhere I should state that a kindred form (Ruticilla leucocyana) is very well known-it could not escape observation. Wonderful as the feat looks, it would therefore seem as though this Scandinavian Bluethroat passed over Europe at a stretch, and if so, I cannot conceive its flight being guided by any landmarks.

Furthermore, there is ground for believing that some of the migrations of many species, particularly of water-birds, are performed at night, when sight, one would think, can be of little use to them. But, to be honest, I must confess that dark, cloudy nights seem to disconcert the travellers. On such nights the attention of others besides myself has often been directed to the cries of a mixed multitude of birds hovering over this and other towns, apparently at a loss whither to proceed, and attracted lyy the light of the street-lamps.

One other point only need I now mention; this is $\mathrm{Mr}$. Romanes's assertion that "in the case of all migratory birds, the younger generations fly in company with the older ones," which is at variance with a statement (hitherto, I believe, uncontroverted) of Temminck's :- "On peut pour un fait que les jeunes et les vieux voyagent toujours séparément, le plus souvent par les routes différentes." (Mían. d'Orn. ed. 2, iii. Introduction, p. xliii. note.)

Miagdalene College, Cambridge, Nov. 2

\section{Insects and the Colours of Flowers}

THERE is one point connected with Mr. Darwin's explanation of the bright colours of flowers which $I$ have never seen referred to. The assumed attractiventss of bright colours to insects would appear to involve the supposition that the colour-vision of insects is approximately the same as our own. Surely this is a good deal to take for granted, when it is known that even among ourselves colour-vision varies greatly, and that no inconsiderable number of persons exist to whom, for example, the red of the scarlet geranium is no bright colour at all, but almost a match with the leaves.

Whittinghame, Preston Kirk

\section{Sounding and Sensitive Flames}

$\Lambda$ SEVERE indisposition, which disabled me from correspondence during nearly the whole of last month, prevented me from acknowledging as soon as it appeared in NATURE (vol. x. p. 244) Prof. Barrett's excellent communication on Sounding and Sensitive Flames, replying to my letter on the same subject at page 233 of this volume. Prof. Barrett supplied me with many useful references, and with one at least the want of which led me to misrepresen his connection with the discovery of sensitive properties in suit. ably adjusted wire-gauze flames, for which I had sought in magazines and journals for some months previously in vain. A note of the original description of Mr. Barry's experiment in NATURE, vol, v. p. $3 \circ$, had in the meantime been pointed out to me in another record of very similar experiments, which is itself also, I have no doubt, the same account of "further experiments with the same kind of flame," that Prof. Barrett cites as appearing in the Fournal of the Franklin Institute for April 1872, to which I have not been able to obtain access. The nearer channel to which I was referred for its perusal is the Philosophical Magazine for June 1872 , where a paper is briefly extracted from the $A$ me rican fournal of Science of the preceding month, describing new experiments with Barry's sensitive flame, by Mr. W. E. Geyer, of the Stevens Institute of Technology, in the United States. By placing a wide tube over the flame at a proper height it became sounding, or, if silent, might be made sensitive in such a way as to sound at the slightest hiss or rustle, and on producing any jingling or tinkling sounds in its neighbourhood. Thus the flame sounded twice on pronouncing to it the word "sensitive," showing its instantaneous affection even by mo. mentary sibilant sounds. By varying the experiment, an opposite condition of the flame was obtained, in which it continued sounding until checked by a hiss or rustle from without. It is observed by the editor of the American Fournal of Science, in a note to Mr. Geyer's paper, that in the number for September 1871, of the Moniteur Scientifique, a form of apparatus and experiment apparently identical with Mr. Barry's is noticed as having been made by Prof, Govi at Turin, and this was a few months prior to the letter in which the account of his experiments is given by Mr. Barry to Prof. Tyndall. Thus the sensitive properties of certain wire-gauze flames, like the property of such flames to excite very readily musical vibrations, may have had many independent discoverers; the value of such discoveries is now, as it must have ever been, the new light which one is capable of throwing upon another. The rapid publication of results urgently requires their frequent collection and comparison together; and this process, pressing and urgent as it is, seldom fails in experienced hands to prove a connection, to bind together a chain of consequences, and to leave a subject in general better explored and embellished with new-found illustrations than it was before. Such was the successful treatment, a few years agro, by Prof. Tyndall, of the question of sounding and sensitive flames, when it was shown by beantiful illustrations of Savart's sensitive water-jets, and by equally ingenious and new experiments with smoke-jets as substitutes for flames, that sensitiveness is a residing property of liquid veins and gas.jets, independently, in the latter case, of their being lighted. The laws of fluid pressure and motion, and apparently foremost of all those of capillary attraction in liquids and of mutual friction and diffusion in gases, and not the energies of heat and conibustion of a flame, preside principally over the observed phenomena. The bifurcated head, or low ruffled brush to which the tall wand-like sensitive jet is suddenly reduced, is but the glowing representation of the form which, if it were visible to the eye, the unlighted jet would, under the same circumstances, be observed to take. This is at least in general terms, and perhaps also in plain and fairly accurate statement of the real facts, the simple result which the collection and elucidation of the most brilliant then known experiments illustrating sensitive flames, led a philosopher of Prof. Tyndall's enlightened sagacity and skill in physical investigations to adopt. There can be no doubt of its substantial correctness in the in. creasing array of cases to which it may be successfully applied. The flame is but an illuminated effigy of some of the lowest parts of the issuing gas column, whether tranquil or disturbed, whose upper parts it removes and replaces by products of combustion. The lower parts are also marred in their form by heat, but not so much as to obliterate the original character, shape, and dimensions of the part of the gas column that it represents. The flame terminates upwards, and ceases to represent the unlighted column further when it has found surface of contact enough with the outer air to effect the complete combustion of the gas. The up-draught of violently heated products of combustion near the base impedes the access of fresh air to parts near the summit of the flame, and it must, besides, deform them otherwise, sometimes even rhythmically, as in the unsteady throbbing flame of an ill-trimmed lamp or of a candle burning in its socket. The noisy roar with which flaring of gas-flames is attended tells us also of the uneven mix. ture of the gas and air supplies with each other in the flame, and reminds us of the rapid fire of small explosions that must probably introduce new sources of confusion in its form. If these explosions, however, are regularly timed, they can be made to maintain the simple musical note of harmonic flames and these flames again, wholly dependent as they appear to be 